\section{Black Currant Clonal Identity and White Pine Blister Rust Resistance}

\author{
Todd A. Burnes and Robert A. Blanchette \\ Department of Plant Pathology, University of Minnesota, 495 Borlaug Hall, \\ 1991 Upper Buford Circle, St. Paul, MN 55108
}

\section{Jason A. Smith ${ }^{1}$ \\ School of Forest Resources and Conservation, University of Florida, 134 Newins-Ziegler Hall, P.O. Box 110410, Gainesville, FL 32611}

\section{James J. Luby \\ Department of Horticultural Science, University of Minnesota, 1970 Folwell Avenue, St. Paul, MN 55108}

Additional index words. Ribes nigrum, white pine blister rust, rust fungus, immunity, forest pathology, alternate host, Pinus strobus

\begin{abstract}
Gooseberries and currants (Ribes L.) are the alternate hosts for the fungus Cronartium ribicola J. C. Fischer, the causal agent of white pine blister rust. In this study, 16 black currant $(R$. nigrum $L$.) cultivars, including three accessions of the putatively immune cultivar 'Consort' and three cultivars developed at the University of Minnesota Horticultural Research Center, were screened for resistance to $C$. ribicola using artificial inoculation procedures. Twelve of these cultivars were grown in the field and observed for natural infection. Cultivars 'Ben Sarek', 'Ben Lomond', and 'C2-2-1' were infected naturally in the field at the University of Minnesota Horticultural Research Center in 2000, 2001, and 2004. Cultivars 'Ben Sarek', one mislabeled 'Consort' accession, R. nigrum 'WI-1', and 'Ben Lomond' had significantly more uredinial sori than other cultivars when inoculated artificially. To determine if the infected and noninfected 'Consort' clones were genetically related, DNA microsatellite genotyping was carried out to fingerprint these clones. One of the six microsatellite loci resulted in a polymorphism that indicated the infected clone was genetically different from the noninfected clones. In addition, the inoculation procedures used in these studies are generally efficacious for predicting resistance in the field because none of the field-infected cultivars were resistant in the greenhouse. This study confirms the $\boldsymbol{C r}$ gene for resistance to $C$. ribicola in Ribes has remained effective for over 50 years.
\end{abstract}

Gooseberries and currants belong to the genus Ribes and include many native species and cultivars used for ornamental plantings and fruit production in North America. Breeding programs in North America and Europe have focused on producing Ribes with desired juice quality, winter hardiness, cultural characteristics, and pest resistance, including tolerance to insects, viruses, and fungi (Brennan, 1995; Dale, 2000; Hummer and Barney, 2002).

Several native and nonnative species of Ribes can serve as alternate hosts for Cronartium ribicola, the causal agent of white pine blister rust (WPBR). This disease was introduced into North America over 100 years ago and has caused major mortality to native five-needle pines. Once the Ribes leaves are infected with aeciospores from the pine, they

Received for publication 28 Mar. 2007. Accepted for publication 24 June 2007.

We are grateful to Dr. Rex Brennan of the Scottish Crop Research Institute and Dr. Kim Hummer of the USDA National Clonal Germplasm Repository for providing plant materials for this study.

${ }^{1}$ To whom reprint requests should be addressed; e-mail jasons@ufl.edu. develop uredinia that produce urediniospores that reinfect Ribes leaves during the summer months (Sinclair et al., 1987). This is followed by the production of telia and basidia in late summer and fall. Basidiospores from basidia do not travel long distances and infect pines through needle stomata (Sinclair et al., 1987). One method of control of this disease in the United States and Canada has been to eradicate native and cultivated susceptible Ribes in areas where five-needle pines grow. This has been discontinued because of its cost and lack of evidence that eradication was successful to reduce the incidence of WPBR (Maloy, 1997). Fifteen states have regulations that prohibit selling or planting of certain Ribes species or cultivars, particularly the nonnative European black currant, $R$. nigrum, that has been found to be extremely susceptible to WPBR (Barney and Hummer, 2005; McKay, 2000). One source of immunity to C. ribicola in Ribes originates from the dominant $\mathrm{Cr}$ gene derived from $\mathrm{R}$. ussuriense (Knight et al., 1972). Ribes ussuriense is very closely related to $R$. nigrum (considered by some to be a variety) and has been used in breeding programs to develop immune cultivars with characteristics similar to $R$. nigrum. There are several named cultivars that origi- nated this way, including 'Consort', 'Coronet', and 'Crusader' (Hunter, 1955). Many Ribes cultivars are sold in nursery centers and promoted for their cultural characteristics and WPBR resistance. Several field and artificial inoculation studies have been completed to determine the relative susceptibility of Ribes cultivars to WPBR (Hummer, 1997, Pluta and Broniarek-Niemiec, 2000; Zambino, 2000). After field evaluations, a red currant (Ribes rubrum L.) cultivar, 'Viking' was thought to have immunity to $C$. ribicola; however, uredinial sori developed after artificial inoculations (Zambino, 2000). It was suggested that an error in labeling or propagation may have occurred and it was wrongly designated as immune. Recently, fingerprinting techniques using random amplified polymorphic DNA and intersimple sequence repeat markers have become available to determine relatedness of Ribes genotypes (Lanham et al., 2000). This technology is useful for verifying accuracy of clones and resistant genotypes.

During a previous study (Burnes et al., unpublished data), it was determined that plants being sold as $R$. nigrum 'Consort' by a wholesale nursery in the United States were very susceptible to WPBR after artificial inoculations. These plants, however, were being marketed as "immune." The objectives of this study were to 1) determine the susceptibility and genetic relatedness of three 'Consort' accessions and 2) determine the WPBR susceptibility of 16 Ribes clones in the field and after artificial inoculations.

\section{Materials and Methods}

Plant materials. Twelve $R$. nigrum accessions used in this study were collected from a germplasm planting at the Horticultural Research Center (HRC), University of Minnesota, Chanhassen, MN. These included clones 'Ben Lomond', 'Ben Sarek', 'Consort' (referred to here as 'Consort-HRC'), 'Golubka', 'Nadezhnaya', 'Titania', three experimental selections ('C2-2-1', 'D16-6-54', and 'D16-8-14') from selections made at the Scottish Crop Research Institute, and three selections from the HRC ('9908 P66' and '9808 P45') both from the cross ('Consort' $X$ 'Ben Lomond') and '9907 P66' ('Crusader' $x$ 'Ben Lomond'). For artificial inoculations, in addition to these cultivars, two accessions ['Consort' (PI 556071) (referred to here as 'Consort-OR') and 'Crusader' (PI 556050)] were obtained from the U.S. Department of Agriculture-Agricultural Research Service (USDA-ARS) National Clonal Germplasm Repository (Corvallis, OR). Two other clones, plants labeled as 'Consort' (referred to here as 'Consort-MN') were from a local wholesale nursery in Minnesota and an unnamed European black currant clone (referred to here as 'WI-1') that previously has been used in WPBR screening studies at the University of Minnesota (Jurgens et al., 2003) were also included in the studies. Cuttings from the current year's terminal growth were taken from each accession used 
in this study and placed into vermiculite and kept in a mist chamber until root formation. After root formation, clones were transplanted into four-inch pots containing a highporosity soilless growing medium and placed in a greenhouse with $18 \mathrm{~h}$ of light in a $24-\mathrm{h}$ period with $21{ }^{\circ} \mathrm{C}$ nighttime and $25{ }^{\circ} \mathrm{C}$ daytime temperatures.

Field observations for white pine blister rust. Plants growing in experimental plantings at the HRC were evaluated for the presence of natural infection by $C$. ribicola in 2000, 2001, and 2004. The following $12 R$. nigrum accessions were included in these evaluations: 'Ben Lomond', 'Ben Sarek', 'Consort-HRC', 'Nadezhnaya', 'Titania', 'C2-2-1', 'D16-6-54', 'D16-8-14', '9908 P66', '9808 P45', '9907 P66', and 'Golubka'. Plants were evaluated for the presence of uredinial sori on approximately Sept. 5 each year (Table 1).

Greenhouse inoculations. Urediniospores $(0.1 \mathrm{~g})$ of C. ribicola strain WI4.1B (Jurgens et al., 2003) were collected from infected $R$. nigrum and added to $400 \mathrm{~mL}$ of sterile $0.025 \%$ purified water agar solution. After adjusting the spore concentration to $\approx 24.4 \times$ $10^{4}$ spores $/ \mathrm{mL}$ using a hemacytometer, a 1-mL spore suspension was sprayed onto the undersides of each of three leaves (leaf size was $\approx 6$ to $7 \mathrm{~cm}$ in diameter) per plant using a handheld sprayer (Jurgens et al., 2003). Four plants with two leaves per plant for each cultivar were inoculated. After inoculation, the tops of each leaf were misted with distilled-deionized water and plants put into a plastic bag, sealed, and placed into a dark chamber at a temperature of $20^{\circ} \mathrm{C}$ for $24 \mathrm{~h}$. A sample of the urediniospore suspension was also sprayed onto a plate of water agar to observe germination rate. These plates were placed into the growth chamber at the same time and conditions as the plants and removed $24 \mathrm{~h}$ after inoculation to calculate urediniospore germination rate using $40 \times$ magnification. After $24 \mathrm{~h}$, plants were removed from bags and placed into a chamber at $20{ }^{\circ} \mathrm{C}$ with a 12 -h light period.

Table 1. Cronartium ribicola uredinial sori development on Ribes cultivars based on observations made of natural infection occurring in the field at the University of Minnesota Horticultural Research Center.

\begin{tabular}{|c|c|c|c|c|}
\hline \multirow{3}{*}{$\begin{array}{l}\text { Ribes } \\
\text { nigrum } \\
\text { cultivars }\end{array}$} & \multicolumn{3}{|c|}{$\begin{array}{l}\text { The presence of } \\
\text { uredinia on leaves }\end{array}$} & \multirow{3}{*}{$\begin{array}{c}\text { Sample } \\
\text { size }\end{array}$} \\
\hline & \multicolumn{3}{|c|}{$\mathrm{Yr}$} & \\
\hline & 2000 & 2001 & 2004 & \\
\hline Ben Sarek & + & + & + & 15 \\
\hline Ben Lomond & + & + & + & 15 \\
\hline C2-2-1 & + & + & + & 15 \\
\hline D-16-8-14 & - & - & - & 15 \\
\hline D-16-6-54 & - & - & - & 15 \\
\hline Titania & - & - & - & 15 \\
\hline Consort HRC & - & - & - & 2 \\
\hline 9908 P45 & - & - & - & 1 \\
\hline 9908 P66 & - & - & - & 1 \\
\hline 9907 P66 & - & - & - & 1 \\
\hline Golubka & - & - & - & 2 \\
\hline Nadezhnaya & - & - & - & 2 \\
\hline
\end{tabular}

After $35 \mathrm{~d}$ of incubation, uredinial sori were counted in an area defined by a $2-\mathrm{cm}$ diameter ring placed in the center of each of three apical sections (lobes) per leaf of each cultivar for a total of 24 areas per cultivar (Table 2). The presence or absence of telia was also recorded. The mean number of uredinial sori that developed on leaves of the different Ribes cultivars were compared with Tukey's multiple comparison using Statistix 7 (Analytical Software, Tallahassee, FL) (Table 2).

Microsatellite genotyping. Microsatellite (simple sequence repeat) markers were used to determine the genetic relatedness of the three different accessions of Ribes nigrum labeled as 'Consort'. Genomic DNA was extracted using the Qiagen DNeasy plant mini-kit (Qiagen, Valencia, CA) according to the manufacturer's instructions. Microsatellite loci $R J L 1-R J L 6$ were targeted for polymerase chain reaction (PCR) using primers designed for Ribes nigrum by Brennan et al. (2002). PCRs were performed using an MJ Research PTC-100 minicycler (Bio-Rad, Hercules, CA). PCR amplicons were visualized on $1.5 \%$ agarose gels stained with SYBR I green nucleic acid stain. Results were photographed using a digital camera and Dark reader (Clare Chemical Research, Dolores, CO).

\section{Results}

Field observations for Ribes infection by white pine blister rust. Cultivars 'Ben Sarek', 'Ben Lomond', and 'C2-2-1' were naturally infected in the field at the University of Minnesota HRC and uredinial sori were observed on the plants in 2000, 2001, and 2004 (Table 1). The cultivar 'Ben Lomond' had $75 \%$ of the leaves infected in $2000,90 \%$ of the leaves infected in 2002, and $90 \%$ infected in 2004 . 'Ben Sarek' and 'C2-2-1' had less than $1 \%$ of the leaves infected in all 3 years. The remain-

Table 2. Number of uredinial sori on leaves of Ribes nigrum cultivars with Cronartium ribicola inoculated under controlled conditions.

\begin{tabular}{lc}
\hline $\begin{array}{l}\text { Ribes nigrum L. cultivar } \\
\text { identification }\end{array}$ & $\begin{array}{c}\text { Mean number } \\
\text { of uredinial sori } \\
\text { on Ribes leaves }\end{array}$ \\
\hline Ben Sarek & $135.4 \mathrm{a}$ \\
Consort-MN-1 & $121.6 \mathrm{a}$ \\
WI-1 & $107.1 \mathrm{a}$ \\
Ben Lomond & $106.2 \mathrm{a}$ \\
C2-2-1 & $5.1 \mathrm{c}$ \\
Golubka & $0.7 \mathrm{c}$ \\
Consort-HRC & $0.0 \mathrm{c}$ \\
9908 P66 & $0.0 \mathrm{c}$ \\
9907 P66 & $0.0 \mathrm{c}$ \\
Nadezhnaya & $0.0 \mathrm{c}$ \\
D-16-8-14 & $0.0 \mathrm{c}$ \\
Titania & $0.0 \mathrm{c}$ \\
D-16-6-54 & $0.0 \mathrm{c}$ \\
9908 P45 & $0.0 \mathrm{c}$ \\
Consort-OR & $0.0 \mathrm{c}$ \\
Crusader & $0.0 \mathrm{c}$ \\
\hline
\end{tabular}

${ }^{\mathrm{z}}$ Means followed by the same letter were not significantly different using Tukey's (honestly significant difference) comparison of means $(P=0.05)$. ing genotypes had no signs of infection (Table 1).

Greenhouse inoculations. Results from controlled inoculations showed Ribes cultivars 'Ben Sarek', 'Consort-HRC', 'WI-1', and 'Ben Lomond' had significantly more uredinial sori than did ' $\mathrm{C} 2-2-1$ ' and 'Golubka' (Table 1). The remaining accessions had no signs of infection. All cultivars that became infected also developed telia. The average rate of urediniospore germination on water agar was $56 \%$.

Microsatellite genotyping. Successful PCR amplification was obtained for five of six microsatellite loci tested (RJL1, RJL2, RJL3, RJL5, RJLO). One of the five microsatellite loci, $R J L 2$, displayed a polymorphism indicating that the infected clone, 'Consort-MN', was genetically different from, but likely related to, the noninfected clones of 'Consort' ('Consort-HRC and 'Consort-OR') (Fig. 1). No polymorphisms were observed for the other loci.

\section{Discussion}

The successful cultivation of Ribes for fruit production in North America will depend on development and deployment of C. ribicola-resistant cultivars. The $R$. nigrum cultivars 'Ben Sarek', 'Ben Lomond', and 'C2-2-1' in this study demonstrated susceptibility to $C$. ribicola similar to other results observed in a previous study (Hummer, 1997). Cultivar 'Golubka' developed uedinial sori in the inoculation trials but not in the field. This may be attributed to the high inoculum load during artificial inoculation because 'Golubka' is a derivative of $R$. dikuscha and a cross between susceptible 'Saunders' and resistant 'Pimorskij Cempion' cultivars (Brennan, 1995). This cultivar should be tested on a wider scale to determine if it will become infected under field conditions. Regional differences in virulence may occur among strains of C. ribicola, and the strain used in this study to inoculate cultivars may differ in virulence than others found in North America. However, in a study by Zambino (2000), 21 different strains of $C$. ribicola from different states showed no significant differences in infection on Ribes.

The clones '9908 P66', '9907 P66', and '9808 P45' were selected at the University of Minnesota HRC because they exhibited no blister rust infection and had high fruit productivity and an upright growth habit suitable for mechanical harvest. All are from crosses between the susceptible cultivar 'Ben Lomond' and resistant cultivars, either 'Consort' or 'Crusader' (Table 1). Their immunity to WPBR in this study suggests that they may possess the $C$. ribicola resistance gene, $\mathrm{Cr}$, from the 'Consort' or 'Crusader' (Brennan, 1995; Knight et al., 1972). The Scottish selections are from crosses involving Ribes with WPBR-resistant parents. The resistance they exhibited in the inoculation trials demonstrated that a high level of resistance can be selected in the field. If this resistance is the result of $\mathrm{Cr}$, then this resistance gene is still 


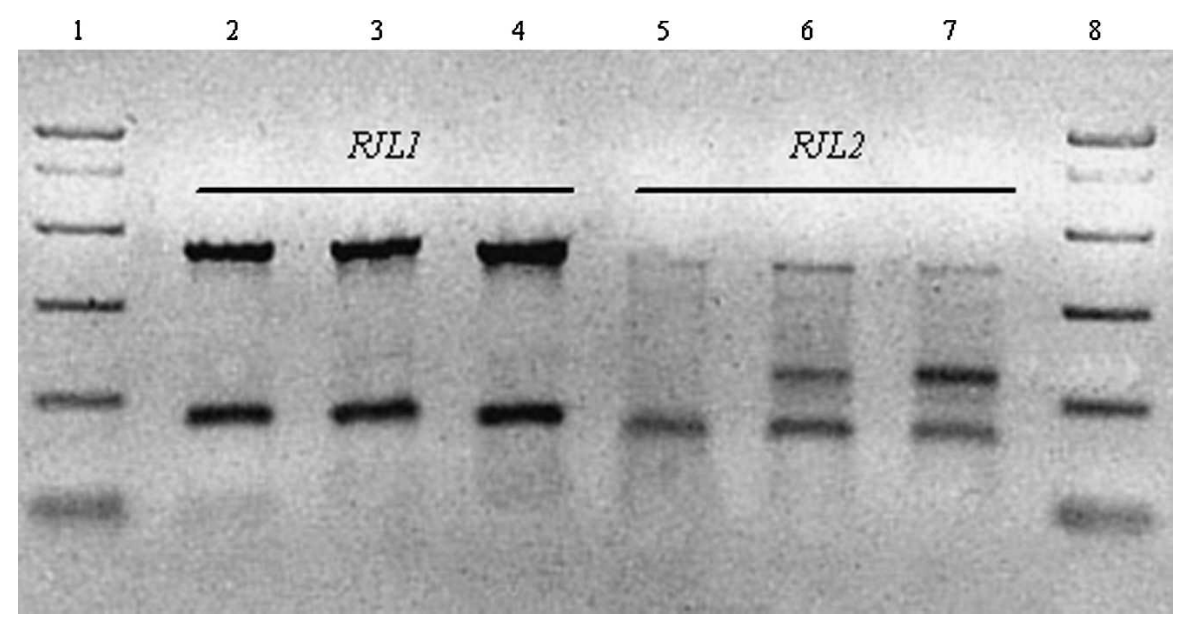

Fig. 1. Photograph of a SYBR green-stained agarose gel showing homogeneity $(R J L 1)$ and polymorphism (RJL2) at two of six Ribes nigrum microsatellite loci tested. Lanes 1 and 8 contain 100-base pair ladder; lanes 2 and 5 are 'Consort-OR'; lanes 3 and 6 are 'Consort-HRC'; and lanes 4 and 7 are 'Consort-MN'.

effective against $C$. ribicola more than 50 years after its discovery and first deployment.

The accession Consort acquired at a nursery ('Consort-MN') had a similar amount of uedinial sori development as did the susceptible European black currant ('WI1 '). The other 'Consort' accessions from the USDA-ARS National Clonal Germplasm Repository ('Consort-OR') and University of Minnesota HRC ('Consort-HRC') had no uredinial development after artificial inoculations. Molecular fingerprinting confirmed that 'Consort $\mathrm{MN}$ ' differs genetically from 'Consort-OR' and 'Consort-HRC'. This is likely the result of mixing of clones in a nursery and mislabeling. However, because polymorphism was observed at only one of the six loci tested, it is possible that a mutation in the plants grown from cuttings is responsible for their susceptibility. This somaclonal variation is observed frequently with other tissue culture-grown plants. Another possibility that explains the molec- ular similarity is that 'Consort-MN' is a susceptible offspring of 'Consort', perhaps from a seedling that became established in a planting of 'Consort'. Further testing would be required to verify this. Regardless of the reason for the variation, the potential impact for the horticultural industry and the WPBR pathosystem is significant. In many states, there are restrictions on planting currants or gooseberries with exceptions being made for immune cultivars such as 'Consort'. If these clones are mixed up and wrongly sold as immune, nurseries could be responsible for the further spread of WPBR and regulations put into place by state or local authorities to make sure only immune clones of Ribes are planted would be ineffective.

\section{Literature Cited}

Barney, D.L. and K.E. Hummer. 2005. Currants, gooseberries, and jostaberries: A guide to growers, marketers, and researchers in
North America. Food Products Press, Binghamton, NY.

Brennan, R.M. 1995. Currants and gooseberries, p. 191-295. In: J. Janick and J. Moore (eds.). Fruit breeding, vine and small fruits, Vol. 2. John Wiley and Sons Inc., New York.

Brennan, R.M., L. Jorgensen, M. Woodhead, and J. Russell. 2002. Development and characterization of SSR markers in Ribes species. Mol. Ecol. Notes 2:327-330.

Dale, A. 2000. Potential for Ribes cultivation in North America. HortTechnology 10:548-554.

Hummer, K.E. 1997. Diamonds in the rust: Ribes resistant to white pine blister rust. Fruit Var. J. 51:113-117.

Hummer, K.E. and D.L. Barney. 2002. Currants. HortTechnology 12:377-387.

Hunter, A.W. 1955. Black currants, p. 28-29. Progress report of the Cent. Exp. Farm. Agr. Canada, Ottawa 1949-1953.

Jurgens, J.A., R.A. Blanchette, P.J. Zambino, and A. David. 2003. Histology of white pine blister rust in needles of resistant and susceptible eastern white pine. Plant Dis. 87:1026-1030.

Knight, R.L., J.H. Parker, and E. Keep. 1972. Abstract bibliography of fruit breeding and genetics 1956-1969. Rubus and Ribes. Tech. Commun. Commonw. Bur. Hort. Plantation Crops 32.

Lanham, P.G., A. Korycinska, and R.M. Brennan. 2000. Genetic diversity within a secondary gene pool for Ribes nigrum L. revealed by RAPD and ISSR markers. J. Hort. Sci. Biotechnol. 75:371-375.

Maloy, O.C. 1997. White pine blister rust control in North America: A case history, p. 87-109. In: R.K. Webster (ed.). Ann. Rev. Phyt. Annual Review Inc., Palo Alto, CA.

McKay, S. 2000. State regulation of Ribes to control white pine blister rust. HortTechnology 10:562-564

Pluta, S. and A. Broniarek-Niemiec. 2000. Field evaluation of resistance to white pine blister of selected blackcurrant genotypes in Poland. HortTechnology 10:567-569.

Sinclair, W.A. and H.H. Lyon. 2005. Diseases of trees and shrubs. 2nd ed. Cornell Univ. Press, Ithaca, NY.

Zambino, P.J. 2000. Evaluating white pine blister rust resistance in Ribes after artificial inoculation. HortTechnology 10:544-545. 